\title{
Coupling of nitrogen cycling, primary productivity and phytoplankton dynamics during the end-Ordovician mass extinction
}

\author{
YAN CHEN $^{12}$, ChUNFANG CAI ${ }^{2 *}$, WeI LIN ${ }^{1 *}$ \\ ${ }^{1}$ Key Laboratory of Earth and Planetary Physics, Institute of \\ Geology and Geophysics, Chinese Academy of Sciences, \\ Beijing 100029, China \\ ${ }^{2}$ Key Laboratory of Petroleum Resource Research, Institute of \\ Geology and Geophysics, Chinese Academy of Sciences, \\ Beijing 100029, China \\ (*correspondence: cai_cf@mail.iggcas.ac.cn, \\ weilin0408@gmail.com)
}

The end of Ordovician witnessed profound changes of global climate and oceanic redox conditions, and a major catastrophe for marine organisms, namely the end-Ordovician mass extinction. During this event, planktonic and benthic faunas and microbial communities were substantially influenced. Previous modelling and experimental investigations have suggested that an increased supply of exogenous nutrients could support larger phytoplankton and higher productivity. Consequently, changes in the community structure of microorganisms could provide useful clues for nutrients dynamics and primary productivity.

Here, we report the investigation of organic carbon accumulation rates and nitrogen isotopes from an OrdovicianSilurian section located in Chongqing Municipality, China. Our results, combined with other published organic carbon data in the tropical and subtropical oceans, indicate that the primary productivity could have dropped to its lowest and small phytoplankton may have dominated the ecosystem during the sea level lowstands and Hirnantian glaciation maximum. However, at the eve and aftermath of Hirnantian glaciation, primary productivity were high and large phytoplankton could have thrived in the lowerlatitude oceans. Low primary productivity could have resulted from oligotrophy in the tropical and subtropical waters as evidenced by the nitrogen isotope ratios during Hirnantian low sea levels, while high productivity could have been fueled by abundant $\mathrm{NH}_{4}^{+}$or $\mathrm{NO}_{3}{ }^{-}$sourced from upwellings before and after the Hirnantian glaciation. The coupled evolution of nitrogen cycling, primary productivity and phytoplankton indicates the collapse of food chain base during the end-Ordovician mass extinction. Microbial community could have changed in the tropics and subtropics, though its link to mass extinction event of macroscopic faunas needs further investigation. 